\title{
Congenital self-healing reticulohistiocytosis with spontaneous regression*
}

\author{
Leela Rani Parimi ${ }^{1}$ \\ Liu Hong ${ }^{1}$
}

\author{
Jiabao You ${ }^{1}$ \\ Furen Zhang ${ }^{1}$
}

DOI: http:/ / dx.doi.org/10.1590/abd1806-4841.20175432

\begin{abstract}
Congenital self-healing reticulohistiocytosis is a rare, benign, self-limiting variant of Langerhans cell histiocytosis $(\mathrm{LCH})$. LCH encompasses a group of idiopathic disorders characterized by the clonal proliferation of Langerhans cells. Congenital self-healing reticulohistiocytosis typically appears at birth or in the neonatal period as isolated cutaneous lesions, often appearing as multiple crusted papules with no systemic findings. Although clinical features seem aggressive, the lesions tend to involute spontaneously within weeks to a few months leaving residual hypo or hyperpigmented macules. Timely diagnosis with histology, immunocytochemistry, and electron microscopic studies will eliminate unnecessary therapeutic interventions. Although mostly self-resolving, it carries a variable clinical course in some patients with cases of extracutaneous involvement and/or recurrences. Hence, reassurance and long-term follow-up play key roles in the management of this disease.
\end{abstract}

Keywords: Congenital abnormalities; Histiocytosis; Langerhans cells

\section{INTRODUCTION}

Langerhans-cell histiocytosis ( $\mathrm{LCH}$ ) encompasses a group of idiopathic disorders, previously described under the rubric "histiocytosis X." LCH is now recognised as a clonal proliferative disorder of Langerhans cells juxtaposed against a backdrop of hematopoietic cells, including T-cells, macrophages, and eosinophils. ${ }^{1} \mathrm{~A}$ congenital, self-healing form of histiocytosis was first described by Hashimoto and Pritzer in $1973 .{ }^{2}$ It is a rare, benign variant of LCH, typically seen at birth or in the neonatal period, characterized by the presence of skin lesions with no internal organ involvement. The mucous membrane is also spared. Lesions regress spontaneously within weeks to a few months, leaving residual hypo or hyperpigmentation.

\section{CASE REPORT}

A four-month-old baby girl was brought to our clinic with multiple crusted red-brown papules distributed throughout her body, including the scalp. Multiple hypopigmented macules were also present (Figure 1). She was a healthy, full term infant born to a 28-year-old primigravida by normal vaginal delivery. History revealed that her lesions on the torso existed from birth, while lesions on the legs erupted a few days later. Her mother recalled that, by the end of third month, some of the lesions begin to regress spon-
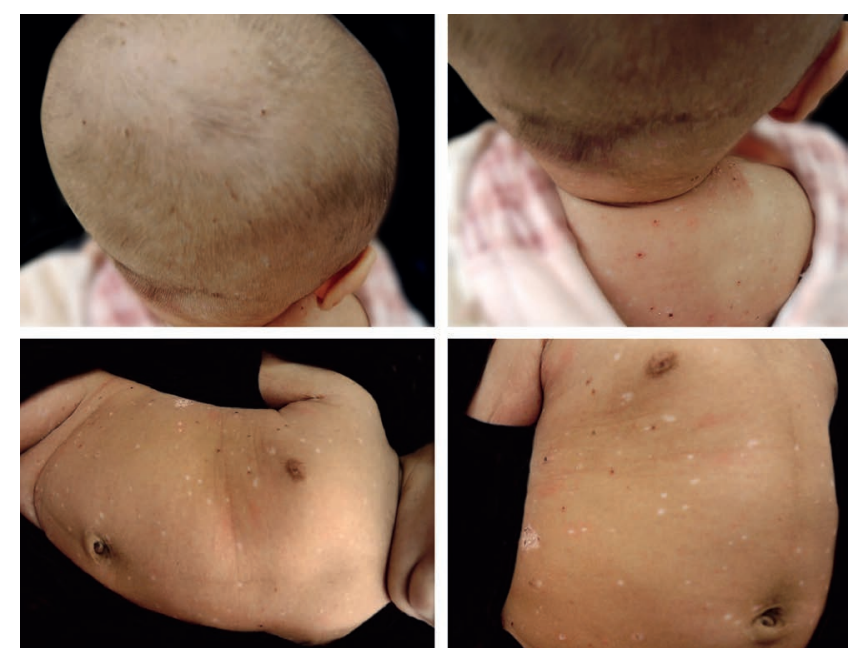

Figure 1: Crusted reddish-brown papules distributed throughout the body, including the scalp. Multiple hypopigmented macules were also noted

\section{Received on 27.11.2015}

Approved by the Advisory Board and accepted for publication on 06.03.2016

* Work performed at the Shandong Provincial Hospital of Dermatology and Venereology, Shandong University, Jinan, Shandong, China.

Financial support: none.

Conflict of interest: none.

1 Department of Dermatology, Shandong Provincial Hospital of Dermatology and Venereology, Shandong University, Jinan, Shandong, China. 
taneously. She was diagnosed in other hospitals as eczema and was treated with some traditional drugs, which proved to be of little benefit. Physical examination revealed the distribution of hemorrhagic crusts throughout her body. New lesions continued to appear while the older ones had subsided, leaving behind hypopigmented lesions. The mucous membrane was not involved. No hepatomegaly, splenomegaly, or lymph node enlargement was observed. Her weight and growth were within normal percentiles.

Complete blood count, serum urea, creatinine, bilirubin, and liver enzymes were within normal limits. Skeletal survey, chest radiography, and abdominal ultrasound seemed unremarkable, and a biopsy was requested. Histopathology revealed focal erosion and crusting of the epidermis. Within the dermis, there was a dense infiltrate of large and round mononuclear cells, some of which contained folded nuclei and eosinophilic cytoplasm, suggestive of histiocytes (Figure 2). The nuclei were of various shapes and sizes, from irregularly round to oval or kidney-shaped without atypia. In immuno-histochemistry, these cells were CD1a and S-100 positive, consistent with LCH. Direct immunoflouroscence demonstrated an intact dermoepidermal junction (Figure 3). Electron microscopy was not performed. The patient's clinical course with spontaneous resolution at the time of presentation confirmed the diagnosis of CSHRH. We followed the "wait and watch" approach and the baby's family members were reassured. After three months, all of the lesions, except those on the scalp, were completely cured, leaving areas of hypopigmentation (Figure.4). The patient was called again after three months for follow-up.

\section{DISCUSSION}

The working group of the Histiocyte Society has divided histocytic disorders into 3 groups: (A) dendritic cell histiocytosis, (B) macrophage-related disorders, and (C) malignant histiocytosis. ${ }^{3} \mathrm{LCH}$ is a rare condition that occurs in 3-5 children per million per year. LCH belongs in group 1 and encompasses a spectrum of diseases, including Letterer-Siwe disease, eosinophilic granuloma,

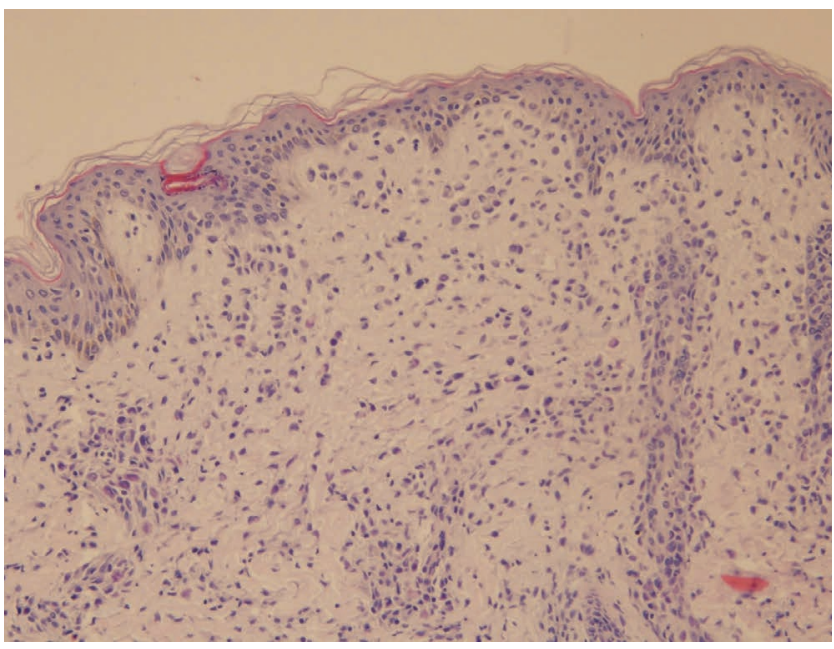

FIGURE 2: Histology revealed a diffuse dermal infiltrate of large histiocytes with reniform nuclei and scattered eosinophils (Hematoxylin \& eosin, X40)

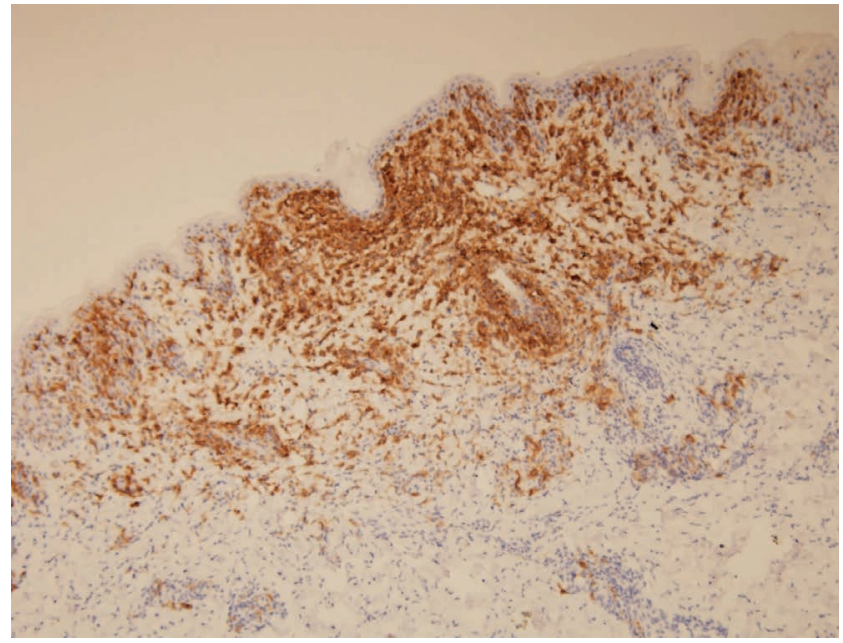

FIGURE 3: Immunohistochemistry shows CD1a expression by histiocytes (Hematoxylin \& eosin X200)
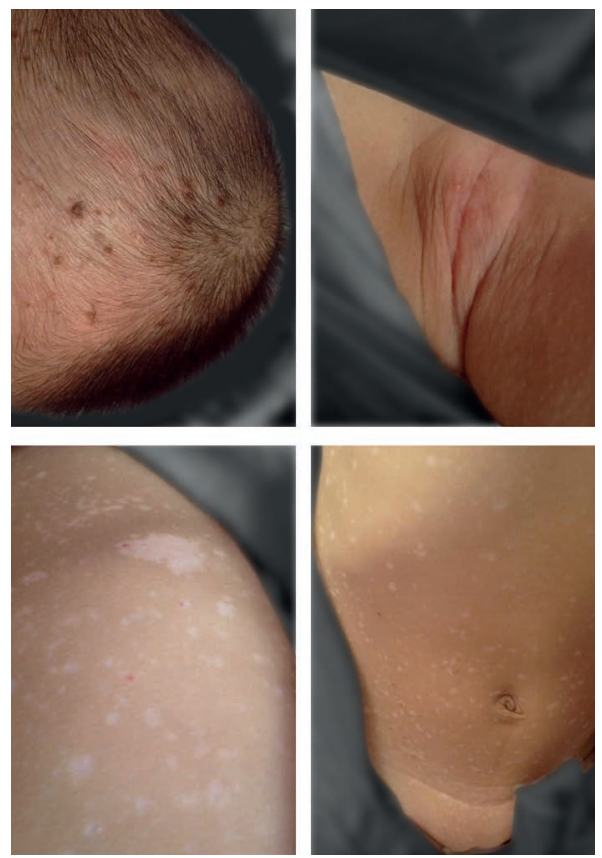

Figure 4: After three months, almost all of the lesions regressed spontaneously, leaving residual hypopigmentation.

Hand-Schüller-Christian disease, and a congenital self-healing form. It is a disorder of the antigen-processing cells known as histiocytes or Langerhans cells. The etiology of LCH is unknown, but neoplasia, immune stimulation, and dendritic cell disorders have been implicated in its pathogenesis. ${ }^{4}$ It mainly affects children and is commonly recognized as a sporadic disorder.

Congenital self-healing reticulohistiocytosis (CSHRH) or Hashimoto-Pritzker disease is a congenital self-healing form of $\mathrm{LCH}$, manifesting as cutaneous eruptions at birth or during the early postnatal period. There are a multitude of presentations with CSHRH, but it typically presents as a scattered cutaneous eruption of multiple, firm, painless, red, pink, violaceous, or brownish papules and nodules that may develop crusts and vesicles. The vesicles 
may be pseudovesicular and often develop central ulceration. ${ }^{5}$ Unusual variants may appear as hemorrhagic bullae, urticarial plaques with a positive Darier signs, "blueberry muffin"-like lesions, or even molluscum-like papules. ${ }^{2,6,7}$ In rare cases, solitary lesions are also reported. ${ }^{8}$ Solitary CSHRH seems to represent about $20-25 \%$ of the patients among all cases of CSHRH (5). The lesions usually involute spontaneously, within an average of 3 months, but have been reported to take up to 1.5 years, leaving residual post-inflammatory hyper- or hypopigmentation. ${ }^{9}$ In most cases, the infants are otherwise healthy with no evidence of systemic involvement. However, symptoms of organ involvement with or without spontaneous regression and relapses have been reported. Clinical relapses may involve skin, mucosa, bone, thymus, and the pituitary gland. ${ }^{8}$ Diabetes insipidus has also been reported during follow-up. ${ }^{9}$

The differential diagnosis of a newborn with hemorrhagic papulovesicles is broad and includes numerous infections and neoplastic disorders. Infectious disorders to consider would include HSV, varicella, cytomegalovirus, syphilis, toxoplasmosis, rubella, congenital candidiasis, bullous impetigo, and listeriosis. Neoplastic disorders to consider in a newborn with papulovesicles are congenital leukemia, $\mathrm{LCH}$, and neuroblastoma. Also in the clinical differential of erythematous papulovesicles are neonatal pustular melanosis, erythema toxicum neonatorum, incontinentia pigmenti, neonatal hemangiomatosis, and extramedullary hematopoiesis, as well as non- $\mathrm{LCH}$, including juvenile xanthogranulomas, generalized eruptive histiocytoma, and indeterminate cell histiocytoma. ${ }^{10}$

Initial clinical and histopathological findings cannot differentiate between the spectrum of $\mathrm{LCH}$ disorders. Hence, an extensive systemic evaluation, including routine blood tests and radiological examinations, needs to be conducted to rule out the fulminant variants. Topical or systemic therapies are generally not required in CSHRH. Timely diagnosis with histology, immunocytochemistry, and electron microscopic studies will eliminate unwanted therapeutic interventions. Due to shorter follow-up periods in most of the reported cases, the relapse and mortality rates in CSHRH are underestimated. Thus, a more consistent follow-up is required. Most of the reported relapses occurred during the first year of life. ${ }^{5}$ Hence, a monthly follow-up is advised during the first year. To conclude, reassurance and long-term follow-up are recommended to monitor for relapse or progression into a systemic disease for skin-only LCH. $\square$

\section{REFERENCES}

1. Kakkar S, Kapila K, Verma K. Langerhans cell histiocytosis in lymph nodes cytomorphologic diagnosis and pitfalls. Acta Cytol. 2001;45:327-32.

2. Inuzuka $\mathrm{M}$, Tomita $\mathrm{K}$, Tokura $\mathrm{Y}$, Takigawa $\mathrm{M}$. Congenital self-healing reticulohistiocytosis presenting with hemorrhagic bullae. J Am Acad Dermatol. 2003:48:S75-7.

3. Satter EK, High WA. Langerhans cell histiocytosis: a review of the current recommendations of the Histiocyte Society. Pediatr Dermatol. 2008;25:291-5.

4. Brazzola P, Schiller P, Kühne T.Congenital self-healing langerhans cell histiocytosis with atrophic recovery of the skin: clinical correlation of an immunologic phenomenon. J Pediatr Hematol Oncol. 2003;25:270-3.

5. Larsen L, Merin MR, Konia T, Armstrong AW. Congenital self-healing reticulohistiocytosis: concern for a poor prognosis. Dermatol Online J. 2012;18:2.

6. Butler DF, Ranatunge BD, Rapini RP. Urticating Hashimoto-Pritzker Langerhans cell histiocytosis. Pediatr Dermatol. 2001:18:41-4.

7. Shaffer MP, Walling HW, Stone MS. Langerhans cell histiocytosis presenting as blueberry muffin baby. J Am Acad Dermatol. 2005:53:S143-6.

8. Lee YH, Talekar MK, Chung CG, Bell MD, Zaenglein AL. Congenital self-healing reticulohistiocytosis. J Clin Aesthet Dermatol. 2014;7:49-53.

9. Esterly NB, Maurer HS, Gonzalez-Crussi F. Histiocytosis X: a seven-year experience at a children's hospital. J Am Acad Dermatol. 1985;13:481-96.

10. Walia M1, Paul P, Mishra S, Mehta R. Congenital Langerhans cell histiocytosis: the self-healing variety. J Pediatr Hematol Oncol. 2004;26:398-402.

\author{
MAILING ADDRESS: \\ Furen Zhang \\ Shandong Provincial Institute of Dermatology \\ and Venereology, \\ 27397 Jingshi Road, \\ Jinan, \\ 250022 Shandong Province, China. \\ E-mail: zhangfuren@hotmail.com
}

How to cite this article: Parimi LR, You J, Hong L, Zhang F. Congenital self healing reticulohistiocytosis with spontaneous regression. An Bras Dermtatol. 2017;92(4): 553-5. 